\title{
THE EFFECT OF LOW TO MODERATE PRENATAL ALCOHOL EXPOSURE AND BINGE DRINKING EPISODES ON DRAW-A-PERSON AT AGE 5 YEARS
}

\section{Correspondence to}

Jacquelyn Bertrand, Centers for Disease Control and Prevention, 1600 Clifton Rd, Atlanta, GA 30333.

Email: jbertrand@cdc.gov

Linda Uglvig Jensen ${ }^{1}$, Hanne-Lise Falgreen Eriksen ${ }^{1}$, Claire Marchetta ${ }^{2}$, Megan Reynolds ${ }^{2}$, Jasmine R. Owens ${ }^{2}$, Clark H. Denny ${ }^{3}$, Ulrik Schiøler Kesmodel ${ }^{4,5}$, Erik Lykke Mortensen ${ }^{1} \&$ Jacquelyn Bertrand $^{3}$

${ }^{1}$ Institute of Public Health and Center for Healthy Aging, University of Copenhagen, Denmark

${ }^{2}$ Oak Ridge Institute for Science and Education, Oak Ridge Tennessee, USA

${ }^{3}$ Centers for Disease Control and Prevention (CDC), Atlanta, Georgia, USA

${ }^{4}$ Departments of Obstetrics and Gynaecology, Aarhus University Hospital, Aarhus, Denmark

${ }^{5}$ Department of Clinical Medicine, Aarhus University, Denmark

Disclaimer: The findings and conclusions of this report are those of the authors and do not necessarily represent the official position of the Centers for Disease Control and Prevention.

'Running head': prenatal alcohol exposure and draw-a-person skills

Key words: prenatal alcohol exposure, visual-motor skills, drawing, draw-a-person 


\begin{abstract}
This study examined the effects of maternal alcohol consumption and binge drinking during pregnancy on children's Draw-A-Person (DAP) scores. Participants were 1,533 5-year-olds from the Danish National Birth Cohort. Regression analyses revealed an adverse effect of nine or more drinks per week. A drop in mean DAP score of 6.26 (95 \% CI: -12.24; -0.39) was observed in the fully adjusted model. A significant interaction between average weekly consumption and binge episodes also was observed.

Findings suggest that prenatal exposure to moderate weekly doses of alcohol and binge drinking episodes are associated with lowered scores on the DAP
\end{abstract}

\section{Introduction}

Research and clinical science has consistently demonstrated that prenatal exposure to alcohol is a

significant teratogen for the human brain (Greene, et al., 1991; Mattson et al., 2010). Depending on the frequency, amount, and timing of in utero exposure, as well as other extant factors (e.g., genetics, nutrition, environment, etc.), alcohol has been shown to have adverse effects on all

neurodevelopmental domains including intelligence, motor skills, executive functioning, learning, memory, and attention. One area of particular vulnerability is grapho-motor skills (Kopera-Frye \& Zielinski, 1995; Uecker \& Nadel, 1996). Grapho-motor/visual-spatial coordination is an area of functioning that appears to cascade into difficulty with higher order cognitive functions such as math concepts and skills later in development (Kable \& Coles, 2003; Kable \& Coles, 2007).

Negative effects of heavy alcohol exposure on short and long-term outcomes in children are well- documented. But whether these effects are observed at low to moderate maternal consumption during pregnancy has not been demonstrated (Clarren, 1986). To date, most studies have failed to observe adverse neurodevelopmental effects at lower levels of prenatal alcohol exposure. Areas investigated include intelligence, motor skills, attention, and executive functioning (Alati et al., 2008; Fried, O'Connell, \& Watkinson, 1992; Kelly et al., 2009; Kelly et al., 2012; Kelly et al., 2013; Kesmodel et al., 2012a;
O’Leary, Taylor, Zubrick, Kurinczuk, \& Bower, 2013), although grapho-motor skills have not been studied specifically.

The intertwined risk of chronic (average) drinking and binge episodes is not completely understood. While most research to date has focused on chronic alcohol consumption, there is growing evidence that the blood alcohol concentration (BAC) of the mother is the major factor that determines the impact on the fetus (Goodlett, Horn, \& Zhou, 2005; Maier, Miller, \& West, 1999). Brain growth is particularly susceptible to high BACs (Kelly et al., 2012) and some human studies suggest that binge drinking during pregnancy may be associated with poor neurodevelopmental outcomes (Henderson, Kesmodel,

\& Gray, 2007; Streissguth, Barr, \& Sampson, 1990). While few pregnant women drink alcohol on a daily basis, many women report isolated episodes of binge drinking (five or more drinks on a single occasion), particularly before pregnancy is recognized (Kesmodel, Kesmodel, Larsen, \& Secher, 2003; Kesmodel, 2001). Thus, potential effects of binge drinking episodes are another important issue which should be further investigated.

Recognizing the need for additional research on the effects of neurodevelopmental outcomes among children whose mothers consumed alcohol during pregnancy, data from the Lifestyle During Pregnancy Study (LDPS) were examined. The LDPS (Kesmodel et al., 2010) is a large Danish prospective follow- up study of mothers (with data about alcohol consumption 
during pregnancy) and neurodevelopmental outcomes among their 5-year-old children. Previous analyses from this dataset have been reported elsewhere for intelligence (Falgreen Eriksen et al., 2012; Kesmodel et al., 2012b), attention

(Underbjerg et al., 2012), executive functioning (Skogerbø et al., 2012) and behavioral problems (Skogerb $\varnothing$ et al., 2013). Findings indicated negative effects for children of women drinking 9 or more drinks per week. Analysis of this sample for the effects of maternal binge drinking on intelligence, attention or executive functioning, did not yield consistent findings, although most analyses showed no observable effect.

The aim of the present study was to examine the effects of low to moderate maternal alcohol consumption and binge drinking during pregnancy on children's grapho-motor skills as measured by the Draw-a-Person Intellectual Ability Test for Children, Adolescents and Adults (DAP). In addition, correlation between performance on the DAP and IQ, as measured by the Wechsler Preschool and Primary Scale of Intelligence-Revised (WPPSI-R; Wechsler, 1999), was explored. Finally, the relation between average weekly consumption and binge drinking patterns was examined.

\section{Methods}

\subsection{Participants}

The study was approved by the DNBC Board of Directors, the DNBC Steering committee, the regional Ethics Committee, the Danish Data Protection Agency, and the Institutional Review Board at the Centers for Disease Control and Prevention. Signed informed consent was obtained for the LDPS.

Participants were sampled from the Danish National Birth Cohort (DNBC) (Kesmodel et al., 2012a; DNBC, 2010), a large prospective study of 101,042 pregnant Danish women and their children. Participants were recruited in 1997-2003 at their first prenatal visit by their general practitioner. Based on information on alcohol consumption before and during pregnancy, 3,478 women and their children were invited to a 5-year follow-up examination in the Lifestyle During Pregnancy Study (LDPS) (Kesmodel et al., 2012a); of those, 1,782 (51\%) participated in a three hour individual test session. Specific criteria for extraction of potential participants for the present study from the DNBC are described in detail elsewhere (see Kesmodel et al., 2010).

The present analysis includes 1,533 children with available drawings and their mothers (95 children failed to complete a drawing, complete the test battery, or had other missing data). An additional 154 children were excluded due to inability to speak Danish, having impaired hearing or vision causing inability to complete the cognitive tests, being a multiple birth, and/or having congenital diseases likely to cause intellectual disability (e.g. Down Syndrome) (see Kesmodel et al., 2012a).

At the age of 60-64 months, the children participated in a comprehensive psychological assessment of global and specific cognitive functions. The full test battery is described elsewhere (Kesmodel et al.,

2012a). Testing took place in four major cities of Denmark (Copenhagen, Odense, Aalborg, and Aarhus). Test procedures were standardized in detail and carried out by ten trained psychologists blinded to the children's exposure status. Tester differences were taken into account by the inclusion of indicator variables in the statistical analyses.

\subsection{Measures}

\subsubsection{Exposure assessment}

The information on alcohol consumption during the index pregnancy was obtained from a telephone interview conducted with all women included in the DNBC (median, 17 weeks of gestation; range 7-39 weeks of gestation) (DNBC, 2010). The information included data on the average number of drinks per week of beer, wine, and spirits currently consumed at the time of the prenatal interview, as well as a 
second question about consumption before pregnancy. The definition of a drink followed the definition from the Danish Health and Medicines Authority, with one standard drink being equal to $12 \mathrm{~g}$ of pure alcohol. Average consumption was categorized into strata of weekly exposure: $0,1-4, \quad 5-8$, and $\geq 9$. Additional information was obtained on the number of binge episodes (i.e., an intake of five or more drinks on a single occasion), and the timing (gestational week) of these episodes (Kesmodel et al., 2012a).

\subsubsection{Outcome variables}

The DAP test was administered as part of the LDPS test battery. Standard administration of the DAP was used (Reynolds \& Hickman, 2004). The child was given a blank sheet of paper and a pencil and then asked to draw a boy or girl (consistent with the child's own gender). The child was given 5 minutes to complete the drawing.

The DAP was scored according to standardized criteria outlined in the American DAP manual (Reynolds \& Hickman, 2004). In this scoring system, 21 components of the drawing, (head/face, arms/hand, legs/feet, accessories, etc.), are assigned $0-4$ points depending on presence, degree of details and dimensioning. Total raw score had a possible range from 0 to 49 . One modification to the coding system was that "crowns" were not scored as an accessory since it is traditional for girls to receive "princess outfits" for the 5 th birthday and approximately $32 \%$ of girls included them which could have introduced a gender artifact. Drawings were scored by trained coders who were blind to the child's exposure status and were not part of the data collection team. Inter-rater reliability of scoring was assessed for ten percent of the drawings and ranged from 89 to 100 percent agreement $($ Kappa $=0.86(p<0.01)$.

The American DAP manual provides conversion of raw scores to an IQ scale, but it was considered problematic to use these norms for Danish children. Consequently, scaled scores were developed by normalizing raw scores to an IQ scale with mean $=100$ and SD $=15$ in the total Danish sample. Analyses were conducted and are reported for both the raw scores and the normalized IQ scores.

\subsubsection{Covariates}

A large number of covariates were included and specifics of how they were operationalized are described elsewhere (see Kesmodel et al., 2010). Information on the following variables was obtained from the prenatal telephone interview and included: parity, prenatal maternal smoking, and maternal pre-pregnancy body mass index (BMI). A questionnaire administered at the 5-year follow-up provided information on the following variables: maternal marital status, parental education, an index of the quality of postnatal family/home environment, maternal depression, current maternal as well as paternal alcohol intake, child health status (including medications), postnatal parental smoking, and child's hearing and vision. Maternal age was obtained from the Danish Civil Registration System, as were the age and sex of the child. Birth weight (grams) and gestational age (days) were obtained from the Danish Medical Birth Registry.

Maternal IQ and child IQ were assessed at the follow-up examination. Child IQ was assessed using the Wechsler Primary and Preschool Scales of Intelligence-Revised (WPPSI-R) (Wechsler, 1999), one of the most widely used tests of intelligence for children aged three to seven years. For practical reasons,

we used a short version comprising three verbal subtests: Arithmetic, Information, and Vocabulary; and three non-verbal subtests: Object Assembly, Block Design, and Geometric Design. Standard

procedures were used to prorate IQs from the shortened form of the tests (Wechsler, 1999). Because no Danish WPPSI-R norms were 
available at the time of the study, Swedish norms were used to derive scaled scores and IQs.

Maternal verbal IQ was assessed using two verbal subtests (information and vocabulary) from the Wechsler Adult Intelligence Scale (WAIS) (Wechsler, 1995) and the Raven's Standard Progressive Matrices provided nonverbal IQ (Raven, 1958). Raw scores of each test were standardized based on the results from the full sample, and were weighted equally in a combined score that was restandardized to an IQ scale with a mean of 100 and an SD of 15.

\section{Statistical analysis}

All statistical analyses were conducted with Stata 11 (StataCorp LP, College Station, TX, USA), and

were weighted by sampling probabilities with robust variance estimation. Statistical tests were two- tailed and declared significant at the 5\% level. Estimates are accompanied by $95 \%$ confidence intervals.

The number of missing values in each of the variables ranged from 0 to 32 . Missing values were imputed by modeling variables through analysis of patterns of other variables in the dataset considered to be most predictive (specific equations are available upon request), thus generating 100 completed data sets. All conclusions were maintained when a complete case analysis was conducted with the

1,525 cases that had complete data for all core confounders and 1,484 cases that had complete data for all potential confounders. The results of the imputed analyses are reported. All imputations were performed with the ice add-on command and the built-in mi estimate command of Stata 11.

Multiple linear regression was used to evaluate the association between alcohol exposure and standardized DAP scores. Maternal average consumption was analyzed as a categorical variable (coded as $0,1-4,5-8$, or 9 or more drinks/week) while binge episodes were analyzed as a binary variable (coded yes/no), and categorical as number of binge episodes (coded $0,1,2$, or 3 or more episodes) and timing of binge episodes (coded week 1-2, week 3-4, week 5-8, or week 9 or later in pregnancy). Because information on timing of binge episodes was missing for 9 mothers, the main analyses of binge drinking comprised 1,524 children.

Parental education, maternal IQ, maternal smoking during pregnancy, the child's age and sex as well as who conducted the test were considered core confounders and adjusted in a separate model. A full model further adjusted for potential confounders, which included maternal age, maternal pre-pregnancy BMI, marital status, parity, postnatal smoking, child postnatal health, hearing, vision and home environment. In the analyses of maternal average alcohol consumption, binge drinking (coded yes/no) was included as a potential confounding factor, whereas the average number of drinks per week consumed by the mother during pregnancy (coded as $0,1-4,5-8$ or 9 or more drinks/week) was included as a potential confounding factor in the analyses of effects of binge drinking.

Interactions between average consumption and a binary binge drinking variable were analyzed with both unadjusted and adjusted models. Since gestational age and birth weight may mediate effects of maternal alcohol consumption, separate analyses including these variables as additional covariates were conducted. Finally, the correlations of DAP IQ with the WPPSI-R Full Scale, verbal, and performance IQs were analyzed both as bivariate correlations and partial correlations controlling for sex.

\section{Results}

Women reporting no average weekly alcohol consumption during pregnancy tended to be younger, 
non-smoking and primiparous, with less education and lower IQ compared to women having consumed 1-4 or 5-8 drinks per week (Table 1). Smoking and suboptimal home environment were more often observed among women consuming 5 units or more per week (Table 1). Median weekly alcohol intake was 1 drink in exposure category $1-4$, five drinks in category $5-8$, and 10 drinks in the 9 or more drinks per week category. Similar characteristics were observed for women who reported no binge episodes in early pregnancy (data not shown) ${ }^{1}$.

Table 1: Sample characteristics across levels of average maternal alcohol intake in pregnancy

\begin{tabular}{|c|c|c|c|c|c|}
\hline & \multicolumn{5}{|c|}{ Average number of drinks per week } \\
\hline & 0 & $1-4$ & $5-8$ & $9+1$ & Total \\
\hline Number of participants & 715 & 630 & 169 & 19 & 1,533 \\
\hline $\begin{array}{l}\text { Samnling fraction } \\
\text { Timing of interview } \\
\text { (Gestational week) }\end{array}$ & $\begin{array}{c}8.0 \\
(1.5 / 49.6) \\
16.0 \\
(13.0 / 23.0)\end{array}$ & $\begin{array}{c}5.5 \\
(1.2 / 22.8) \\
17.0 \\
(13.0 / 24.0)\end{array}$ & $\begin{array}{c}65.6 \\
(34.3 / 76.5) \\
17.0 \\
(13.0 / 23.0)\end{array}$ & $\begin{array}{c}95.0 \\
(57.9 / 95.0) \\
17.0 \\
(12.0 / 28.0)\end{array}$ & $\begin{array}{c}9.7 \\
(1.5 / 49.6) \\
17.0 \\
(13.0 / 23.0)\end{array}$ \\
\hline \multicolumn{6}{|l|}{ Family characteristics } \\
\hline $\begin{array}{l}\text { Maternal age. vears } \\
(\text { Mean } \pm S D)\end{array}$ & $29.8 \pm 4.3$ & $31.4 \pm 4.1$ & $33.1 \pm 4.4$ & $35.2 \pm 4.3$ & $30.9 \pm 4.4$ \\
\hline \multicolumn{6}{|l|}{ Parity } \\
\hline$O(\%)$ & 55.8 & 49.8 & 29.6 & 15.8 & 50.0 \\
\hline $1(\%)$ & 30.8 & 31.1 & 41.4 & 42.1 & 32.2 \\
\hline $2+(\%)$ & 13.4 & 19.0 & 29.0 & 42.1 & 17.8 \\
\hline $\begin{array}{l}\text { Maternal BMI, kg/m² } \\
\text { (Median, 10/90 pctile) }\end{array}$ & $\begin{array}{c}22.7 \\
(19.4 / 29.1)\end{array}$ & $\begin{array}{c}22.6 \\
(19.6 / 28.4)\end{array}$ & $\begin{array}{c}22.5 \\
(19.9 / 27.7)\end{array}$ & $\begin{array}{c}21.6 \\
(18.0 / 29.4)\end{array}$ & $\begin{array}{c}22.6 \\
(19.6 / 28.7)\end{array}$ \\
\hline $\begin{array}{c}\text { Maternal marital status }{ }^{2} \\
\text { Single }(\%)\end{array}$ & 13.0 & 12.1 & 10.3 & 5.3 & 12.2 \\
\hline $\begin{array}{l}\text { Parental education, years } \\
\text { (Median, } 10 / 90 \text { pctile) }\end{array}$ & $\begin{array}{c}12.5 \\
(11.0 / 16.0)\end{array}$ & $\begin{array}{c}13.0 \\
(11.0 / 16.0)\end{array}$ & $\begin{array}{c}13.0 \\
(11.0 / 17.0)\end{array}$ & $\begin{array}{c}12.5 \\
(11.0 / 17.0)\end{array}$ & $\begin{array}{c}13.0 \\
(11.0 / 16.0)\end{array}$ \\
\hline $\begin{array}{l}\text { Familv/home index } \\
\text { Suboptimal }^{3}(\%)\end{array}$ & 18.3 & 15.5 & 26.1 & 35.3 & 17.5 \\
\hline
\end{tabular}

\footnotetext{
${ }^{1}$ Interview questions for average weekly alcohol consumption and binge drinking were asked separately thus a woman could report no average weekly drinking and also a binge episode, however for analyses participants were grouped according to average intake. A total of 266 women reported no average consumption of alcohol and no binge episodes.
} 


\begin{tabular}{|c|c|c|c|c|c|}
\hline Maternal IQ (Mean $\pm S D$ ) & $98.7 \pm 15.1$ & $\begin{array}{c}101.2 \pm \\
14.7\end{array}$ & $\begin{array}{c}100.7 \pm \\
15.8\end{array}$ & $\begin{array}{c}102.4 \pm \\
13.8\end{array}$ & $\begin{array}{l}0.0 \pm \\
15.0\end{array}$ \\
\hline $\begin{array}{l}\text { Maternal smoking in } \\
\text { pregnancy } \\
\quad \text { Smokers }(\%)\end{array}$ & 29.8 & 24.3 & 39.6 & 52.6 & 28.9 \\
\hline $\begin{array}{c}\text { Postnatal parental smoking } \\
\text { Smokers (\%) }\end{array}$ & 30.8 & 31.5 & 39.8 & 52.2 & 32.3 \\
\hline $\begin{array}{l}\text { Maternal binge drinking in } \\
\text { pregnancy }^{4}(\%)\end{array}$ & 65.6 & 77.1 & 58.0 & 42.1 & 69.2 \\
\hline \multicolumn{6}{|l|}{ Child characteristics } \\
\hline $\begin{array}{l}\text { Sex } \quad \text { Male (\%) }\end{array}$ & 48.4 & 52.4 & 56.2 & 52.6 & 50.9 \\
\hline $\begin{array}{l}\text { Age at testing, years } \\
\text { (Median, 10/90 pctile) }\end{array}$ & $\begin{array}{c}5.2 \\
(5.1 / 5.3)\end{array}$ & $\begin{array}{c}5.2 \\
(5.1 / 5.3)\end{array}$ & $\begin{array}{c}5.2 \\
(5.1 / 5.3)\end{array}$ & $\begin{array}{c}5.3 \\
(5.2 / 5.3)\end{array}$ & $\begin{array}{c}5.2 \\
(5.1 / 5.3)\end{array}$ \\
\hline Birth weight, grams & $\begin{array}{r}3600.1 \\
\pm 529.3\end{array}$ & $\begin{array}{r}3612.5 \\
\pm 508.2\end{array}$ & $\begin{array}{r}3552.7 \\
\pm 482.1\end{array}$ & $\begin{array}{c}3426.1 \\
\pm 586.4\end{array}$ & $\begin{array}{r}3597.8 \\
\pm 516.6\end{array}$ \\
\hline $\begin{array}{l}\text { Gestational age, days } \\
\text { (Median, 10/90 pctile) }\end{array}$ & $\begin{array}{c}281.0 \\
(267.0 / 293.0)\end{array}$ & $\begin{array}{c}282.0 \\
(269.0 / 293.0)\end{array}$ & $\begin{array}{c}282.5 \\
(267.0 / 292.0)\end{array}$ & $\begin{array}{c}275.0 \\
(256.0 / 294.0)\end{array}$ & $\begin{array}{c}281.0 \\
(267.0 / 293.0)\end{array}$ \\
\hline $\begin{array}{l}\text { Health status } \\
\text { Condition/medicine }{ }^{5}(\%)\end{array}$ & 3.1 & 2.9 & 5.8 & 5.9 & 3.5 \\
\hline $\begin{array}{l}\text { Hearing abilities } \\
\text { Normal (\%) }\end{array}$ & 96.6 & 94.0 & 95.9 & 84.2 & 95.2 \\
\hline $\begin{array}{l}\text { Vision abilities } \\
\text { Normal (\%) }\end{array}$ & 97.5 & 97.5 & 95.3 & 89.5 & 97.1 \\
\hline
\end{tabular}

1. Range 9-14 drinks/week.

2. Single if single either in pregnancy or at follow-up (60-64 months postpartum).

3. Defined as a score on at least 2 of the following items: single parent household; changes in care giving; day care $>8 \mathrm{hrs} /$ day before age $3 ; 14$ or more days away from home; irregular breakfast meals; maternal depression; high maternal or paternal alcohol use.

4. Defined as intake of 5 drinks or more at one occasion.

5. Medical conditions or regular medications that may influence test performance.

Table 2 shows the results of the main analysis of the association between alcohol exposure categories and scores on the DAP. The unadjusted model showed a small positive, non-significant effect of 1-4 units/per week on DAP raw scores and DAP IQ compared to the reference group. Exposure to 5-8 units/week had a small negative, insignificant effect. Exposure to 9 or more units/week was associated with a significantly lower average DAP IQ compared with the abstaining reference category (mean difference $=8.39,95 \% \mathrm{CI}=-14.58 ;-2.21)$. The number of observations in this group $(9$ or more units/week) was small, however, resulting in a wide CI and high uncertainty as to the size of the true effect. In the analyses, after adjusting for core and potential confounders, a similar pattern was observed with slightly smaller average differences, still insignificant for 1-4 and 5-8 units categories ascompared to the reference. For 9 or more units/week, the effect was still significant after adjustment for core and all potential confounders (mean difference -6.26, 95\% CI -12.14; -0.39). Table 2 shows essentially the same pattern of results for the DAP raw scores. 
Table 2. Associations between maternal alcohol intake in pregnancy and DAP ${ }^{1}$ raw scores and IQ scores.

\begin{tabular}{|c|c|c|c|c|c|c|c|}
\hline \multirow[t]{2}{*}{$\begin{array}{l}\text { Average no. } \\
\text { drinks/week in } \\
\text { pregnancy }\end{array}$} & \multirow[t]{2}{*}{ Mean score } & \multicolumn{2}{|c|}{ Crude } & \multicolumn{2}{|c|}{$\begin{array}{l}\text { Adjusted for core } \\
\text { confounders }^{2}\end{array}$} & \multicolumn{2}{|c|}{$\begin{array}{l}\text { Adjusted for core and } \\
\text { potential confounders }\end{array}$} \\
\hline & & $\begin{array}{c}\text { Mean } \\
\text { Difference }\end{array}$ & $95 \% \mathrm{CI}$ & $\begin{array}{c}\text { Mean } \\
\text { difference }\end{array}$ & $95 \% \mathrm{CI}$ & $\begin{array}{c}\text { Mean } \\
\text { difference }\end{array}$ & $95 \% \mathrm{CI}$ \\
\hline & \multicolumn{7}{|l|}{ Raw score } \\
\hline 0 & 98.95 & references & - & references & - & references & - \\
\hline $1-4$ & 100.52 & 1.57 & {$[-0.63 ; 3.78]$} & 1.61 & {$[-0.33 ; 3.56]$} & 1.51 & {$[-0.49 ; 3.51]$} \\
\hline $9+$ & 90.55 & -8.39 & {$[-14.58 ;-$} & -7.48 & {$[-12.89 ;-2.06]$} & -6.26 & {$[-12.14 ;-0.39]$} \\
\hline \multirow[t]{2}{*}{$p$ value ${ }^{4}$} & & \multicolumn{2}{|c|}{0.007} & \multicolumn{2}{|c|}{0.008} & \multicolumn{2}{|c|}{0.040} \\
\hline & \multicolumn{7}{|l|}{ IQ score } \\
\hline 0 & 12.15 & references & - & references & - & references & - \\
\hline $1-4$ & 12.7952 & 0.64 & {$[-0.33 ; 1.62]$} & 0.65 & {$[-0.21 ; 1.51]$} & 0.61 & {$[-0.28 ; 1.49]$} \\
\hline
\end{tabular}

1. Draw-a-Person Intellectual Ability Test for Children, Adolescents, and Adults.

2. Parental education, maternal IQ, prenatal maternal smoking, the child's sex and age, and tester.

3. Parental education, maternal IQ, prenatal maternal smoking and binge drinking, maternal age, parity, prenatal and postnatal marital status, postnatal parental smoking, maternal pre-pregnancy BMI, the child's sex, age, health status, hearing and vision on the day of testing, family/home environment, and tester.

4. $P$-value for the hypothesis of no difference in attention scores across levels of average alcohol intake. 
As shown in Tables $3 a$ and $3 b$, the results for binge drinking showed small and insignificant differences in DAP raw score and DAP IQ for all binge categories (yes/no, number, and timing of episodes). Analyses testing DAP raw scores for interactions between average consumption and binge drinking episodes showed significant interactions for both the unadjusted $(\mathrm{p}=0.003)$ and adjusted analyses $(\mathrm{p}=$

0.002 and 0.01 for analyses of core and all potential confounders). For analyses of the DAP IQ scores, the corresponding p-values were $0.004,0.003$, and 0.01 . Because of the significant interactions, results of stratified analyses are presented in Tables $4 \mathrm{a}$ and $4 \mathrm{~b}$. For both raw and IQ scores, the tables show only significant associations between average consumption level and DAP score for children of mothers with binge drinking episodes. While the effect was only observed for the small group with a consumption level of 9 or more drinks per week, it is noteworthy that the effect on raw scores was significant for the much larger group of children whose mothers consumed 5-8 drinks per week during pregnancy.

Finally, the significant effect of an average consumption of 9 or more drinks per week remained significant in supplementary analyses including gestational age and birth weight as covariates (results not shown). DAP and WPSSI-R IQ scores showed similar trends across alcohol categories (results not shown).

The correlations between DAP raw scores and WPPSI-R were $0.39,0.25$, and 0.41 (results not shown). The correlations between the DAP IQ and WPPSI-R Full Scale, verbal, and performance IQs were $0.36,0.21$, and 0.38 respectively, while the corresponding partial correlations controlling for sex were $0.33,0.22$, and 0.33 . 
Table 3a. Associations between maternal binge drinking in pregnancy and DAP ${ }^{1}$ raw scores, Denmark 2003-2008

\begin{tabular}{|c|c|c|c|c|c|c|c|}
\hline & \multicolumn{3}{|c|}{ Crude } & \multicolumn{2}{|c|}{$\begin{array}{l}\text { Adjusted for core } \\
\text { confounders }^{2}\end{array}$} & \multicolumn{2}{|c|}{$\begin{array}{l}\text { Adjusted for } \\
\text { potential }\end{array}$} \\
\hline & Mean score & $\begin{array}{c}\text { Mean } \\
\text { difference }\end{array}$ & $95 \% \mathrm{CI}$ & $\begin{array}{c}\text { Mean } \\
\text { difference }\end{array}$ & $95 \% \mathrm{CI}$ & $\begin{array}{c}\text { Mean } \\
\text { difference }\end{array}$ & $95 \% \mathrm{CI}$ \\
\hline \multicolumn{8}{|l|}{$\begin{array}{l}\text { Binge drinking } \\
\text { in }\end{array}$} \\
\hline $\begin{array}{l}\mathrm{N} \\
\mathrm{Y} \\
p-\end{array}$ & $\begin{array}{l}12.27 \\
12.75\end{array}$ & $\begin{array}{c}\text { Reference } \\
0.48 \\
0.230\end{array}$ & {$[-0.30 ; 1.26]$} & $\begin{array}{l}\text { Reference } \\
0.29\end{array}$ & $\begin{array}{l}--0.42 ; 1.00] \\
16\end{array}$ & $\begin{array}{c}\text { Reference } \\
0.13\end{array}$ & {$[-0.60 ; 0.86]$} \\
\hline \multicolumn{8}{|l|}{$\begin{array}{l}\text { Number of binge } \\
\text { drinking episodes in }\end{array}$} \\
\hline $\begin{array}{c}0 \\
1 \\
2 \\
3 \\
p-\end{array}$ & $\begin{array}{l}12.27 \\
12.80 \\
12.63 \\
12.71\end{array}$ & $\begin{array}{c}\text { Reference } \\
0.53 \\
0.36 \\
0.44 \\
0.678\end{array}$ & $\begin{array}{c}- \\
{[-0.33 ; 1.39]} \\
{[-0.76 ; 1.48]} \\
{[-1.07 ; 1.94]}\end{array}$ & $\begin{array}{c}\text { Reference } \\
0.27 \\
0.24 \\
0.54\end{array}$ & $\begin{array}{l}- \\
{[-0.50 ; 1.04]} \\
{[-0.76 ; 1.24]} \\
{[-0.91 ; 1.98]} \\
55\end{array}$ & $\begin{array}{c}\text { Reference } \\
0.16 \\
-0.12 \\
0.45\end{array}$ & $\begin{array}{l}- \\
{[-0.62 ; 0.94]} \\
{[-1.17 ; 0.92]} \\
{[-1.03 ; 1.93]} \\
7\end{array}$ \\
\hline \multicolumn{8}{|l|}{$\begin{array}{l}\text { Timing of binge } \\
\text { drinking episodes in } \\
\text { pregnancy (gestational }\end{array}$} \\
\hline No binge drinking & 12.27 & Reference & - & Reference & - & Reference & - \\
\hline 1 & 12.97 & 0.69 & {$[-0.42 ; 1.81]$} & 0.45 & {$[-0.58 ; 1.48]$} & 0.32 & {$[-0.75 ; 1.40]$} \\
\hline 3 & 12.49 & 0.22 & {$[-0.89 ; 1.33]$} & -0.05 & {$[-1.03 ; 0.92]$} & -0.24 & {$[-1.23 ; 0.75]$} \\
\hline 5 & 13.76 & 1.48 & {$[0.37 ; 2.60]$} & 1.07 & {$[0.01 ; 2.13]$} & 1.02 & {$[-0.03 ; 2.07]$} \\
\hline 9 & 12.67 & 0.39 & {$[-0.76 ; 1.55]$} & 0.54 & {$[-0.54 ; 1.62]$} & 0.33 & {$[-0.79 ; 1.45]$} \\
\hline $\begin{array}{l}\text { Multiple episodes } \\
p-\end{array}$ & 12.44 & $\begin{array}{l}0.16 \\
0.177\end{array}$ & {$[-0.98 ; 1.31]$} & 0.21 & $\begin{array}{l}{[-0.82 ; 1.24]} \\
04\end{array}$ & -0.01 & $\begin{array}{l}{[-1.09 ; 1.07]} \\
8\end{array}$ \\
\hline
\end{tabular}

1. Draw-a-Person Intellectual Ability Test for Children, Adolescents, and Adults.

2. Parental education, maternal IQ, prenatal maternal smoking, the child's sex and age, and tester.

3. Parental education, maternal IQ, prenatal maternal smoking and average weekly alcohol intake, maternal age, parity, prenatal and postnatal marital status, postnatal parental smoking, maternal pre-pregnancy BMI, the child's sex, age, health status, hearing and vision on the day of testing, family/home environment, and tester.

4. $P$-value for the hypothesis of no difference in DAP scores across levels of average alcohol intake. 
Table 3b. Associations between maternal binge drinking in pregnancy and DAP ${ }^{1}$ IQ scores, Denmark 2003-2008

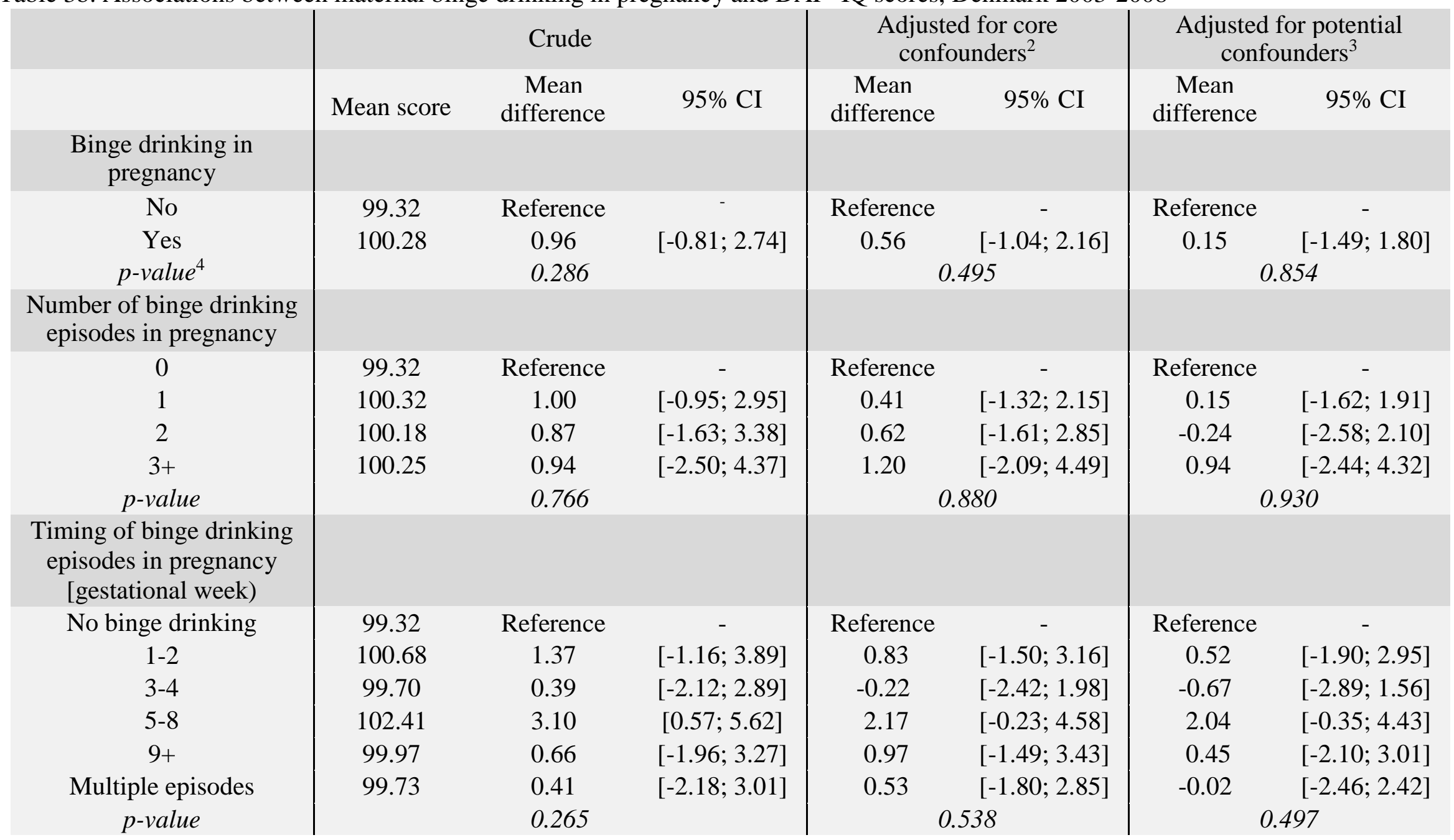

1. Draw-a-Person Intellectual Ability Test for Children, Adolescents, and Adults

2. Parental education, maternal IQ, prenatal maternal smoking, the child's sex and age, and tester.

3. Parental education, maternal IQ, prenatal maternal smoking and average weekly alcohol intake, maternal age, parity, prenatal and postnatal marital status, postnatal parental smoking, maternal pre-pregnancy BMI, the child's sex, age, health status, hearing and vision on the day of testing, family/home environment, and tester.

4. $P$-value for the hypothesis of no difference in DAP scores across levels of average alcohol intake. 
Table 4a. Associations between maternal alcohol intake in pregnancy and $\mathrm{DAP}^{1}$ raw scores by prenatal binge drinking status.

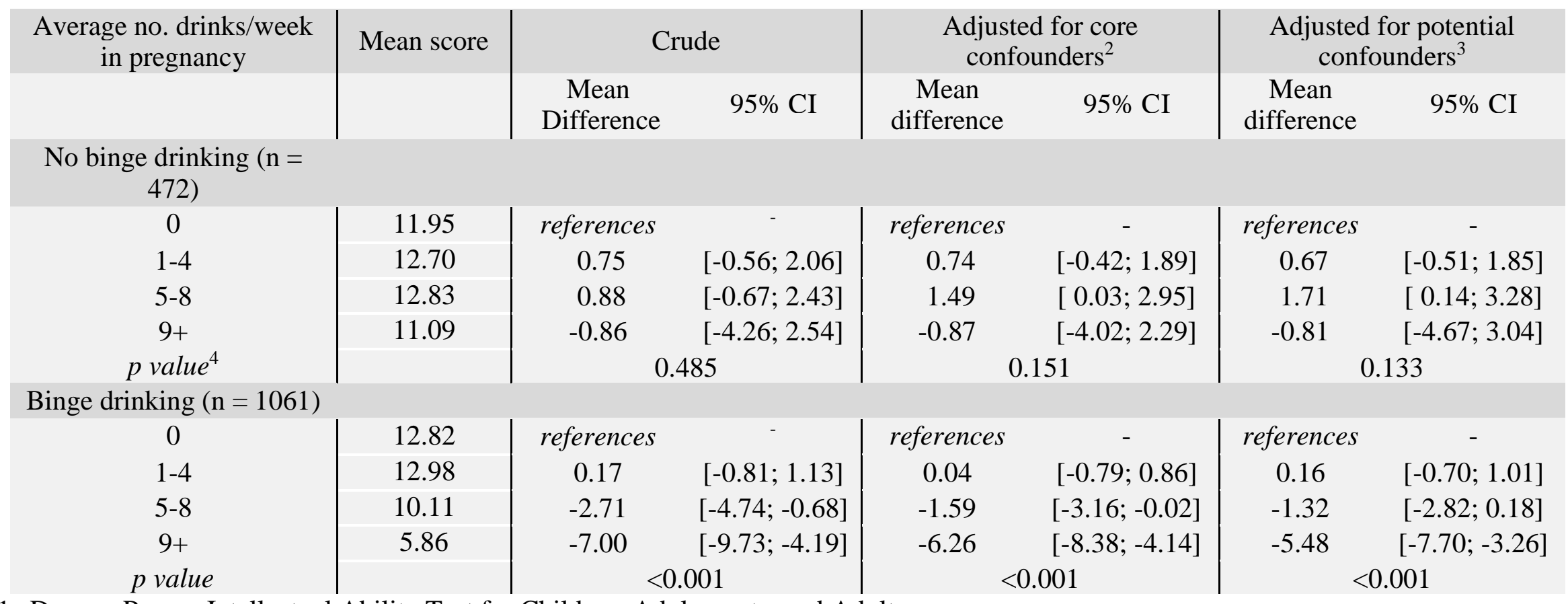

1. Draw-a-Person Intellectual Ability Test for Children, Adolescents, and Adults.

2. Parental education, maternal IQ, prenatal maternal smoking, the child's sex and age, and tester.

3. Parental education, maternal IQ, prenatal maternal smoking and binge drinking, maternal age, parity, prenatal and postnatal marital status, postnatal parental smoking, maternal pre-pregnancy BMI, the child's sex, age, health status, hearing and vision on the day of testing, family/home environment, and tester.

4. $P$-value for the hypothesis of no difference in DAP scores across binge categories. 
Table 4b. Associations between maternal alcohol intake in pregnancy and $\mathrm{DAP}^{1}$ IQ scores by prenatal binge drinking status.

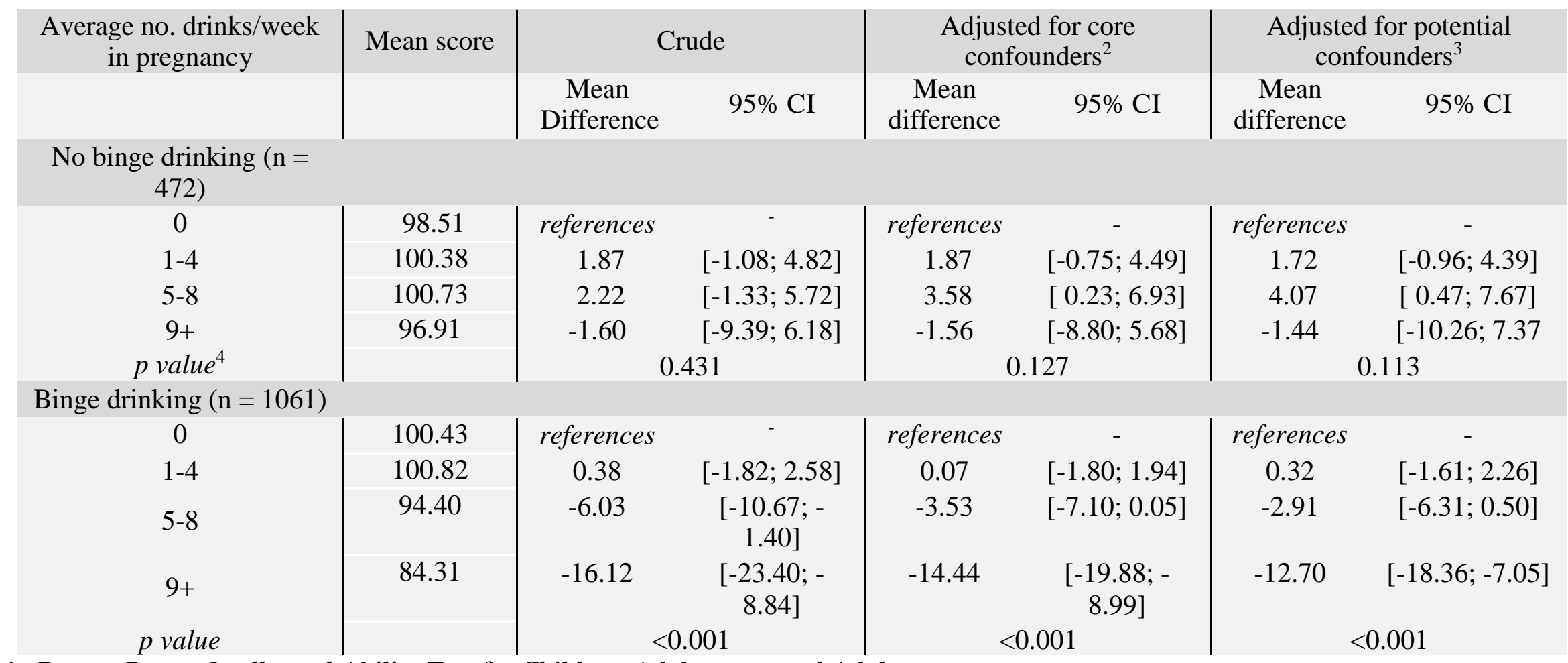

1. Draw a Person Intellectual Ability Test for Children, Adolescents, and Adults

2. Parental education, maternal IQ, prenatal maternal smoking, the child's sex and age, and tester.

3. Parental education, maternal IQ, prenatal maternal smoking and binge drinking, maternal age, parity, prenatal and postnatal marital status, postnatal parental smoking, maternal pre-pregnancy BMI, the child's sex and age, health status, hearing and vision on the day of testing, family/home environment, and tester.

4. $P$ value for the hypothesis of no difference in DAP scores across binge categories. 


\section{Discussion}

This study examined potential effects of low to moderate prenatal alcohol consumption and binge

drinking on grapho-motor skills, as measured by the DAP, of children at age five years. An adverse effect was found for children whose mothers consumed nine or more drinks per week and reported binge episodes during early pregnancy. Children of mothers who drank at this moderate level and binged scored on average 6 points lower compared to children of mothers who did not consume any alcohol during pregnancy. This estimate was, however, accompanied by a wide confidence interval due to the small number of women in this consumption category, but the findings are consistent with previous studies of the LDPS which examined other areas of neurodevelopment (Kesmodel, et al., 2012a). While the majority of children scored within the normal range on the DAP, the lower performance of children with prenatal alcohol exposure as a group that is six points lower compared to children without prenatal alcohol exposure is functionally relevant since it is approximately half a standard deviation. Over the course of development, it would be expected that this gap would widen and children with exposure would encounter more and more difficulty with grapho-motor skills such as learning to write or complete complex assembly tasks.

Previous studies have found significant bivariate correlations between DAP and the WPSSI-R full scale IQ (Reynolds \& Hickman, 2004). This finding was replicated in the present study with a sample of children with prenatal exposure to alcohol. As would be expected, the correlation with performance IQ was higher than with verbal IQ ( 0.38 vs. 0.21$)$. Similar trends were observed across all alcohol exposure categories.

An important finding of this study was the statistically significant interaction between maternal average consumption level and binge drinking episodes during pregnancy. While children whose mothers drank

9 or more drinks per week performed worse on the DAP than children whose mothers did not consume alcohol while pregnant, this effect was more pronounced for children of mothers who in addition to high average consumption also had binge drinking episodes. However, this finding must be viewed with caution given the small number of children in this category. Table 1 shows only 19 children in the category and among these only 8 were children of mothers with binge episodes. Although with such a small sample size the results might be sensitive to weighting according to sampling fractions, a supplementary analysis showed similar results for an unweighted analysis.

If the interaction between average consumption and binge drinking episodes observed for the DAP scores is replicable in future studies, it would reinforce the suggestion of adverse effects being associated with high BAC in very important ways. Although such studies for neurodevelopment are yet to be conducted, a study of fetal death has shown such an effect (Strandberg-Larsen et al., 2008). Clearly, maternal characteristics associated with an alcohol consumption pattern of a relatively high average level in combination with binge drinking episodes must be factored into the fuller picture. The present study tried to address this issue by inclusion of a wide range of potential confounding factors included in statistical models. In particular, this study controlled for parental education and maternal intelligence, which have been shown to be critical in the prediction of child intelligence and other neurodevelopmental functions (Eriksen et al., 2013).

Studies of neurodevelopmental outcomes for children with low to moderate prenatal exposure to alcohol remain challenging and have significant limitations. As with all studies about lifestyle behaviors during pregnancy, 
exposure information may be subject to recall bias. This is especially true for alcohol because of social stigma associated with drinking during pregnancy, although in some locations such as Denmark, this may be less of an issue. Further, this study used only one measure of graphomotor skills, the Draw-a-Person test. It is possible that this measure failed to detect very subtle effects below the exposure level of nine drinks per week or in the absence of binge episodes. Finally, although many covariates were included, the possibility of residual confounding from unaccounted factors remains.

\section{Conclusion}

This study showed decreased performance on the DAP for 5-year-old children who were prenatally exposed to nine or more alcoholic drinks per week and whose mothers experienced binge drinking episodes during early gestation. Very importantly, this study showed a significant interaction between average weekly consumption of alcohol during pregnancy and binge episodes. This finding indicates that studies of neurodevelopmental outcomes in relation to prenatal alcohol exposure should account both for average weekly consumption of alcohol and binge drinking episodes. These findings support recommendations that women should not consume alcohol during pregnancy, and be especially aware of the dangers of binge drinking.

\section{Acknowledgement}

This study was primarily supported by the Centers for Disease Control and Prevention (CDC), Atlanta, Georgia, USA. Additional support was obtained from The Danish National Board of Health, the Lundbeck Foundation, Ludvig \& Sara Elsass' Foundation, the Augustinus Foundation, and Aase \& Ejnar Danielsen's Foundation.
The Danish National Research Foundation has established the Danish Epidemiology Science Centre that initiated and created the Danish National Birth Cohort. The cohort is furthermore a result of a major grant from this Foundation. Additional support for the Danish National Birth Cohort is obtained from the Pharmacy Foundation, the Egmont Foundation, the March of Dimes Birth Defects Foundation, the Augustinus Foundation, and the Health Foundation.

The authors would like to thank the participants for their time and efforts.

Conflicts of interest: none 


\section{References}

Alati, R., Macleod, J., Hickman, M., Sayal, K., May, M., Smith, G. D., \& Lawlor, D. A. (2008).

Intrauterine exposure to alcohol and tobacco use and childhood IQ: Findings from a parental- offspring comparison within the Avon Longitudinal Study of Parents and Children. Pediatr Res 64(6), 659-666.

Clarren, S. K. (1986). Neuropathology in fetal alcohol syndrome in Alcohol and Brain Development

(ed. West, JR) Oxford Press, New York pp 158-166.

Danish National Birth Cohort. Code books for interviews 1-4. (2010). http://www.ssi.dk/English/R\%20and\% 20D/Epidemiology/DNBC/For\%20res earchers/Data\%20 available/Interviews\%201\%20\%204.aspx.

Eriksen, H-L., Kesmodel, U. S., Underbjerg, M., Kilburn, T. R., Bertrand, J., \& Mortensen, E. L. (2013). Predictors of intelligence at the age of 5: Family, pregnancy and birth characteristics, postnatal influences, and postnatal growth. PLoS One, 8(11), e79200.

Falgreen Eriksen, H-L., Mortensen, E. L., Kilburn, T. R., Underbjerg, M., Bertrand, J., Støvring, H., ...

Kesmodel, U. S. (2012). The effects of low to moderate prenatal alcohol exposure in early pregnancy on IQ in 5-yearold children. BJOG, 119, 11911200. DOI:10.1111/j.14710528.2012.03394.x.
Fried, P. A., O’Connell, C. M., \& Watkinson, B. (1992). 60 and 72 month follow-up of children prenatally exposed to marijuana, cigarettes and alcohol: Cognitive and language assessment. $J$ Dev Behav Pediatr, 13, 383-91.

Goodlett, C. R., Horn, K. H., \& Zhou, F. C. (2005). Alcohol teratogenesis: mechanisms of damage and strategies for intervention. Exp Biol Med, 230(6), 394-406.

Greene, T., Ernhart, C. B., Ager, J., Sokol, R., Martier, S., \& Boyd, T. (1991). Prenatal alcohol exposure and cognitive development in the preschool years. Neurotoxicol Teratol, 13(1), 5768.

Henderson, J., Kesmodel, U., \& Gray, R. (2007). Systematic review of the fetal effects of prenatal bingedrinking. Journal of Epidemiology and Community Health, 61(12), 1069-1073.

Kable, J. A. \& Coles, C. D. (2003). Teratology of alcohol: Implications for school settings. In: R. T.

Brown (Ed.). Handbook of Pediatric Psychology in School Settings (pp. 379-404). Mahwah, NJ: Lawrence Erbaum Associates.

Kable, J. A., \& Coles, C. D. (2007). Sociocognitive habilitation using the math interactive learning experience program for alcohol affected children. Alcohol Clin Exp Res, 31, 1425-1434.

Kelly, Y., Iacovou, M., Quigley, M. A., Gray, R., Wolke, D., Kelly, J., \& Sacker, A. (2013). Light drinking versus abstinence in pregnancy behavioural and cognitive outcomes in 7-year-old children: a 
longitudinal cohort study. BJOG, 120(11), 1340-7.

Kelly, Y., Sacker, A., Gray, R., Kelly, J., Wolke, D., \& Quigley, M. A. (2009). Is light drinking in pregnancy, a risk for behavioural problems and cognitive deficits at 3 years of age? Int $J$ Epidemiol, 38(1), 129-40.

Kelly, Y. J., Sacker, A., Gray, R.., Kelly, J., Wolke, D., Head J, \& Quigley, M. A. (2012). Light drinking during pregnancy: still no increased risk for socioemotional difficulties or cognitive deficits at 5 years of age? $J$ Epidemiol Community Health, 66(1), 41-8.

Kesmodel, U. S. (2001). Binge drinking in pregnancy - frequency and methodology. Am $J$ Epidemiol, 154(8), 777-782.

Kesmodel, U. S., Bertrand, J., Støvring, H., Skarpness, B., Denny, C. H., Mortensen, E. L., \& the Lifestyle During Pregnancy Study Group. (2012a). The effect of different alcohol drinking patterns in early to mid pregnancy on the child's intelligence, attention and executive function. BJOG, 119, 1180-1190. DOI: $10.1111 / \mathrm{j} .1471-$

0528.2012.03393.x

Kesmodel, U. S., Falgreen-Eriksen, H-L., Underbjerg, M., Kilburn, T. R., Støvring, H., Wimberley, T.,

\& Mortensen, E. L. (2012b). The effect of alcohol binge drinking in early pregnancy on general intelligence in children. BJOG, 119, 1222-1231. DOI:10.1111/j.14710528.2012.03395.x.
Kesmodel, U. S., Kesmodel, P. S., Larsen, A., \& Secher, N. J. (2003). Use of alcohol and illicit drugs among pregnant Danish women, 1998. Scand J Public Health. 31(1), 5-11.

Kesmodel, U. S., Underbjerg, M., Kilburn, T. R., Bakketeig, L. S., Mortensen, E. L., Landrø, N. I., ...

Thorsen, P. (2010). Lifestyle during pregnancy: Neurodevelopmental effects at 5 years of age. The design and implementation of a prospective follow-up study. Scand $J$ Public Health, 38(2), 208-219.

Kopera-Frye, K. \& Zielinski, S. (1995). Children with fetal alcohol syndrome and fetal alcohol effects: patterns of performance on IQ and visual-motor ability. Technical Report of Southern Utah University: Cedar City, UT. (ERIC document: ED 381 964).

Maier, S. E., Miller, J. A., \& West, J. R. (1999). Prenatal binge-like alcohol exposure in the rat results in regionspecific deficits in brain growth. Neurotoxicol Teratol, 21(3), 285-291.

Mattson S. N,, Roesch, S. C, Fagerlund, Å, Autti-Rämö, I., Jones, K. L., May, P. A., ... \& the Collaborative Initiative on FASDs. (2010). Toward a Neurobehavioral Profile of Fetal Alcohol Spectrum Disorders. Alcoholism: Clinical and Experimental Research. 34(9), 16401650

O'Leary, C. M., Taylor, C., Zubrick, S. R., Kurinczuk, J. J., \& Bower, C. (2013). Prenatal alcohol exposure and educational achievement in children aged 8-9 years. Pediatrics, 132(2), e468- e475. 
Raven, J. C. (1958). Standard

Progressive Matrices. Oxford:

Oxford Psychologists Press.

Reynolds, C. R. \& Hickman, J. A.

(2004). Draw-a-person intellectual

ability test for children

adolescents and adults: Examiner's manual. Austin, TX: Pro-Ed.

Skogerbø, Å., Kesmodel, U, S., Denny, C. H., Kjaersgaard, M. I. S., Wimberley, T., Landrø, N. I. \& Mortensen, E. L. (2013). The effects of low to moderate alcohol consumption and binge drinking in early pregnancy on behaviour in 5-year-old children: A prospective cohort study on 1628 children. BJOG, 120, 1042-1050. DOI: $10.1111 / 1471-0528.12208$

Skogerbø, A., Kesmodel, U. S., Wimberley, T., Støvring, H., Bertrand, J., Landrø, N. I., \& Mortensen, E. L. (2012). The effects of low to moderate alcohol consumption and binge drinking in early pregnancy on executive function in 5-year-old children. BJOG, 119, 1201-1210. DOI: 10.1111/j.1471-0528.2012.03397.x.

Strandberg-Larsen, K., Nielsen, N. R., Grønbæk, M., Andersen, P. K., Olsen, J., Andersen, A. M. (2008). Binge drinking in pregnancy and risk of fetal death. Obstetrics \& Gynecology, 111(3), 602-609. DOI:
Streissguth, A. P., Barr, H. M., \& Sampson, P. D. (1990). Moderate prenatal alcohol exposure: Effects on child IQ and learning problems at age $71 / 2$ years. Alcohol Clin Exp Res, 14(5), 662-669.

Uecker, A. \& Nadel, L. (1996). Spatial locations gone awry: Object and spatial memory deficits in children with fetal alcohol syndrome. Neuropsychologia, 34, 209-223.

Underbjerg, M., Kesmodel, U. S., Landrø, N. I., Bakketeig, L. S., Grove, J., Wimberley, T., ... Mortensen, E. L. (2012). The effects of low to moderate alcohol consumption and binge drinking in early pregnancy on selective and sustained attention in 5-year-old children. BJOG, 119:1211-1221. DOI: 10.1111/j.14710528.2012.03396.x.

Wechsler, D. (1995). Manual for the Wechsler Adult Intelligence Scale. New York, NY: The Psychological Corporation.

Wechsler, D. (1999). Manual for the Wechsler Preschool and Primary Scale of Intelligence Revised.

Swedish Version. Stockholm: Psykologiforlaget AB.

10.1097/AOG.0b013e3181661431 